\title{
O dia em que o Brasil parou: A morte de Tancredo Neves como cerimônia midiática
}

\author{
Marialva Barbosa *
}

\begin{abstract}
Resumo
O texto tem por objetivo estudar a forma como a televisão brasileira constrói a representação da morte. A partir da emissão do Jornal Nacional, da Rede Globo de Televisão, desvelando o desfecho da agonia que vitimara o então presidente eleito, Tancredo Neves, em 21 de abril de 1985, procura-se mostrar como a televisão construiu uma cerimônia em torno do acontecimento morte. A emissão ao vivo do velório e sepultamento de Tancredo Neves, como cerimônia midiática produz uma espécie de suspensão do tempo e procura, mediante uma série de estratégias, conseguir a adesão do público ao espetáculo. Este texto apresenta resultados da pesquisa "Mídia e Cerimônias. Uma análise do modelo cerimonial da televisão brasileira", financiada pelo $\mathrm{CNPq}$.
\end{abstract}

Palavras-chave: Televisão-Cerimônia-Morte-Tancredo Neves

A morte tem ocupado um lugar privilegiado na televisão. Personagens emblemáticos, midiáticos ou oriundos da violência urbana que domina as cidades surgem na tela da TV sob a égide da morte. Dois movimentos podem ser visualizados: de um lado, a morte dos personagens políticos e públicos, os mitos nacionais; de outro, a morte anônima, fruto do espetáculo da violência.

Neste texto nos interessa uma morte em particular, uma morte que parou o Brasil em 1985: a morte do então presidente recém-eleito Tancredo Neves.

Ainda que a morte tenha sido na contemporaneidade negada e expurgada, por mais paradoxal que possa parecer, ela ocupa lugar de destaque na mídia. E, com ela, os rituais contemporâneos recriam as tradicionais cerimônias da morte em outra dimensão.

* Professora do Programa de Pós-Graduação em Comunicação, da Universidade Federal Fluminense (Brasil). E-mail: mcb1@terra.com.br

Este texto foi elaborado graças à pesquisa empírica desenvolvida pela bolsista de iniciação científica (PIBIC-CNPq) Renata Machado dos Santos.

Comun. Inf., v. 7, n. 1, p.62-79, jan./jun. 2004 


\section{4}

Na morte celebrada na cena da TV, publicizada pelas imagens, observa-se a celebração da morte, que inclui a despedida e o cortejo fúnebre pelas principais vias da cidade. $\mathrm{O}$ corpo, conduzido no alto do carro do Corpo de Bombeiros e coberto pela Bandeira Nacional, faz com que a imagem do morto seja substituída pela imagem do seu cortejo e do público que dele participa.

A idéia de viagem associada à morte nunca desapareceu da consciência popular. A viagem começa com o cortejo fúnebre, do qual participam não apenas o público concentrado nas ruas e avenidas, mas também os que assistem as mesmas cenas via transmissão da TV.

Eé essa lógica da viagem que as imagens mostradas na televisão, em todas as mortes midiáticas, destacam. Não se deve mostrar a face do moribundo nem o jazigo e, muito menos, o sepultamento. O que importa é o cortejo, as cenas de despedida, com lenços brancos sendo acenados, o choro convulsivo, o olhar de tristeza e a caminhada. As cenas da viagem é que orientam a lógica narrativa das mortes midiáticas.

A emissão do Jornal Nacional, principal jornal da televisão brasileira, de 21 de abril de 1985 é exemplar dessa apropriação da imagem da morte pela mídia. A edição transmite para todo o país o fim da agonia do presidente Tancredo Neves, após 37 dias de uma longa enfermidade, começa com a imagem da cantora Fafá de Belém cantando o Hino Nacional. O som continua ao fundo e várias imagens do presidente em vida transcorrem natela. Em todas elas, a sua íntima relação como público. São priorizadas também as imagens onde esse mesmo público torna-se multidão: os comícios e os discursos em praça pública.

Após essas cenas, outras imagens do público, agora particularizadas em rostos anônimos, começam a ser transmitidas: uma menina chora, um grupo reza em frente ao hospital. Há aqueles que freqüentam missas em favor da recuperação do presidente. A seguir, o destaque é para um garoto ajoelhado rezando. Uma senhora idosa chora, enquanto outra olha, pensativa, o horizonte.

Enquanto no cerimonial tradicional da morte havia uma série de atos esperados - o lamento da vida, o perdão dos que rodeavam o moribundo e o esquecimento do mundo - na cena midiática não há leito de morte. A morte se dá na cena pública, nos atos de público.

Sem leito, sem tempo para os rituais, é necessário dar à morte caráter dramático e excessivo. A tranqüilidade do leito é substituída Comun. Inf., v. 7, n. 1, p.62-79, jan./jun. 2004 
pelas imagens do público, nas quais excesso é a palavra de ordem. $\mathrm{O}$ morto cerimonial é expiado em atos celebratórios e dramáticos. $\mathrm{O}$ choro da multidão é convulsivo, as cenas de desespero se sucedem. Acentua-se o caráter dramático do momento comunhão.

Após as cenas de abertura, nas quais o principal ator é o público, aparece a imagem do então porta-voz do presidente, Antônio Brito, que faz o anúncio oficial da morte de Tancredo Neves, no Jornal Nacional, exibido em cadeia nacional pela Rede Globo de Televisão. "Lamento informar que o Ex. Sr. Presidente da República, Tancredo de Almeida Neves, faleceu esta noite, às 10 horas e 23 minutos. Acrescento o seguinte: nos últimos cinqüenta anos a vida pública de Tancredo Neves confundiu-se com os sonhos e com os ideais brasileiros de união, de democracia, de justiça social e de liberdade. Nos últimos meses, pela vontade de Tancredo Neves, essas idéias se transformaram na Nova República. A emocionante corrente de fé e de solidariedade das últimas semanas enquanto o presidente Tancredo lutava pela vida só fez crescer esse sentimento de união, que sempre foi ação, exemplo e objetivo de Tancredo Neves. Com a mesma fé, com a mesma determinação, o Brasil haverá, a partir de agora, de realizar os ideais do líder que acabamos de perder: Tancredo Neves". (Jornal Nacional, emissão de 21 de abril de 1985).

A televisão construiu a narrativa em torno desse acontecimento, promovendo uma espécie de suspensão do tempo. Durante horas, o público pôde acompanhar o cortejo, o velório e o sepultamento do primeiro presidente brasileiro civil depois de mais de 20 anos de ditadura militar, como havia acompanhado, durante mais de um mês, a agonia em torno da sua doença.

Após o anúncio oficial da morte, o que se destaca na transmissão é a emoção na voz do locutor Sergio Chapelin e dos repórteres que passam a transmitir ao vivo as emissões. Símbolos nacionais são reconfigurados na tela de TV: forma-se uma cruz com duas fitas, verde e amarela. Ao longe, o Hino Nacional, agora ao som de uma viola, dava o toque cívico necessário à morte emblemática. Os símbolos da pátria eram lembrados no momento final do personagem que ocupara durante 38 dias a tela da TV.

Na construção engendrada para o anúncio da morte, o início da promulgação de uma nova era: a Nova República.

Comun. Inf., v. 7, n. 1, p.62-79, jan./jun. 2004 
"Dr. Tancredo, o senhor nos deixa entre lágrimas de saudades, a certeza de que haveremos de viver uma nova república. Esse sentimento não nos consola, mas faz de todos nós filhos órfãos de um pai entregue a seu povo um legado de esperança e de fé. Liderança e conciliação que imortalizava a sua peregrinação por este penoso mundo dos homens. Como estadista, o senhor nos deixa uma admirável lição de esperança; como pessoa humana, o senhor sacrificou-se até a morte. O senhor foi histórico, foi bravo ao longo de um martírio de trinta e nove dias. No seu martírio Dr. Tancredo, o senhor conseguiu fortalecer mais que nunca a abençoada virtude do nosso povo, que sabe reunir na mesma corrente de amor, o sentimento religioso e o sentimento cívico. Que Deus abençoe a herança cívica e espiritual do Dr. Tancredo Neves, homem símbolo de um novo tempo. Ele nos deixa a patriótica lição do país que tem fé e é capaz de ressuscitar" (Jornal Nacional, 21 de abril de 1985).

Apresentando todas as características de um ritual, as cerimônias da televisão são construídas, graças aos artifícios narrativos - imagens que se sucedem sem cessar, apagamento do contexto, lentidão dos movimentos, repetição dos efeitos, entre muitos outros--, numa espécie de festa comunhão, da qual o telespectador é convidado a fazer parte. A cerimônia televisiva é uma espécie de religião, da qual cada um participa à sua maneira, com seus atos particulares. Situando-se no limiar entre o sagrado e o profano, veicula, na verdade, atos de devoção, nos quais a crença é reforçada pela repetição e pela imitação.

As imagens da população em torno do Instituto do Coração, onde morreu o Presidente, se sucedem. O repórter complementa:

"Vocês estão vendo aí pessoas que estão nas proximidades do Instituto do Coração, sentindo com a sua dor esses momentos graves vividos em frente a essa parte do Hospital das Clínicas (...). Nós vamos mostrar mais uma vez a rua Enéas Carvalho de Aguiar, lembrando que neste momento a falta que a gente sente aqui é daquelas numerosas pessoas que durante dias com chuva, com sol, com frio, não arredaram o pé daqui. Muitas delas sem comer, sem dormir; rezando, de todas as religiões, de todos os credos, não deixando morrer o último fio de esperança pela recuperação do Presidente Tancredo Neves, o que infelizmente não aconteceu. $\mathrm{O}$ Presidente faleceu às 10:23h desta noite (...)". (Idem)

Interrompendo o fluxo dos programas, as cerimônias televisivas

Comun. Inf., v. 7, n. 1, p.63-79, jan./jun. 2004 
interferem diretamente no quotidiano dos telespectadores, lançandoos em outro registro de experiência. Organizadas fora do espaço da mídia, são acontecimentos que ocorrem longe dos estúdios, cabendo à televisão transmiti-los e, sobretudo, produzi-los .

A sua principal característica é se desenrolar no instante mesmo de sua produção. São emissões ao vivo, difíceis de ser controladas e dependentes do padrão de organização e desenvolvimento tecnológico das emissoras. Seus produtores são normalmente representantes do Estado (sociedade civil ou política), com autoridade suficiente para requisitar a atenção do público. Mesmo assim, em vez de desempenhar papel auxiliar, a mídia tende a absorver a organização do acontecimento, impondo regras próprias.

E, por último, são emissões anunciadas e planejadas previamente, $o$ que permite ao público antecipar o próprio acontecimento, preparandose para ele. Um clima de espera instaura-se e é explorado ao máximo.

No que diz respeito à forma expressiva, Daniel Dayan(1996) identifica quatro características gerais: a primeiraé a natureza protocolar da narrativa, sobressaindo as atitudes de reverência. Além disso, o desenrolar do acontecimento tem natureza cerimonial. Assim, os comentaristas intervêm brevemente, propondo análises rápidas, assim como também as críticas são escassas. Freqüentemente, as intervenções publicitárias são excluídas.

A outra característica discursiva é a exaltação de personalidades caracterizadas como fora do comum. Celebrando iniciativas emanadas do poder hegemônico, apresentam as personalidades e o próprio acontecimento como históricos. Daí a naturalidade com que procuram atrair vastas audiências.

Pode-se, pois, falar de uma espécie de obrigação de assistir à emissão. Os telespectadores interiorizam essa norma, celebram o acontecimento, reunindo-se em torno da TV, assistindo em grupos e vestindo-se muitas vezes adequadamente para a ocasião. Isso é o que se observa, por exemplo, nos campeonatos mundiais de futebol, quando os telespectadores reúnem-se nas casas dos amigos, em restaurantes, em bares, no meio da rua, para, juntos, verem o espetáculo da televisão. Na cena pública da assistência, os uniformes dão o tom da participação na comunhão-espetáculo instaurada pela televisão.

Por último, há que se destacar o fato de o discurso assumir a forma de minimização do conflito, reforçando a integração e destacando a Comun. Inf., v. 7, n. 1, p.63-79, jan./jun. 2004 
reconciliação. Como um ritual, as cerimônias da televisão permitem matizar os conflitos e convertê-los em força capaz de manter o sistema. Para isso, celebram a sua inserção em uma história institucional e social, como momento fundador, em que há uma ruptura com o tempo anterior e a inclusão / eclosão de um novo tempo. Caracterizam-se pela fundação de um instante singular, indicando o início de um novo tempo.

Tudo isso pode ser observado na cerimônia que coroou o desfecho da agonia do primeiro presidente civil brasileiro, após a ditadura militar, Tancredo Neves. A ruptura provocada por sua morte - encenada também de maneira ritual no dia da morte de Tiradentes - instaurava não só a construção de um novo mártir, mas o início de um tempo que seria radicalmente diferente do precedente. A partir do desfecho trágico e da martirização do personagem político, também ele, Tancredo Neves, transformava-se em herói salvador que, dando a vida pela causa política, instaurava outra história para o país.

"Aos 75 anos, doente, martirizado, Tancredo de Almeida Neves lutou sem desesperar, movido por sua confiança no futuro do Brasil. Vamos rezar pela alma do Dr. Tancredo, que é a própria alma de seu povo. Vamos rezar e acreditar como ele sempre acreditou no futuro do Brasil. Pátria amada, mãe gentil, nesta hora queremos ouvir o teu hino, queremos cantar juntos, Pátria amada Brasil". (Jornal Nacional, emissão de 21 de abril de 1985)

A voz do apresentador Sérgio Chapelin era interrompida novamente pelo som do Hino Nacional, cantado pela cantora Fafá de Belém. E novamente repetiam-se as mesmas imagens: a cruz ornada com fitas verde e amarela.

Depois da visão do repórter, ao vivo, informando que após a missa de corpo presente, no próprio Instituto do Coração, o corpo seria liberado seguindo para Brasília, num carro do Corpo de Bombeiros e a uma velocidade de 10 quilômetros horários, o apresentador retomava a narrativa para apresentar um documento de memória sobre o personagem Tancredo Neves.

A emissão preparava, assim, a cerimônia que viria a seguir: o cortejo. A informação de que o corpo seria guiado pelas ruas de São Paulo, em carro do Corpo de Bombeiros, mas sobretudo a ênfase à velocidade do veículo, era uma espécie de convite público para que os espectadores participassem daquela cerimônia. A televisão construía lentamente a Comun. Inf., v. 7, n. 1, p.63-79, jan./jun. 2004 
cerimônia midiática, da qual ela era promotora, divulgadora e personagem.

Mas preparar a cerimônia é também construir o personagem digno daquele desfecho. Assim, a emissão vai mesclando aspectos do presente com a construção memorialística de Tancredo Neves. Recorda-se a sua infância na cidade de São João Del Rei, a sua juventude aplicada e, sobretudo, o personagem político que deveria passar para a história.

Em off, o narrador do Jornal Nacional informa:

"Advogado, Tancredo Neves começou a carreira política como vereador neste salão (imagens do salão vazio) em São João Del Rei. Em 54, foi nomeado Ministro da Justiça do segundo governo de Getúlio Vargas, tinha 44 anos. Viveu a crise. O governo liderava uma campanha demolidora, liderada pelo jornalista Carlos Lacerda. Os militares (imagens do Brigadeiro Eduardo Gomes) exigiam a renúncia do presidente. Na noite de 23 de agosto, Getúlio Vargas reúne pela última vez o Ministério. Os risos não escondem a gravidade da situação. Fim da reunião, Getúlio Vargas deu a caneta dele de presente ao Ministro Tancredo Neves. Horas depois, matou-se com um tiro no coração. No enterro de Vargas, em São Borja, no Rio Grande do Sul, Tancredo Neves era um dos mais emocionados. Em 56, foi conselheiro do presidente JK e conseguiu contornar com habilidade a rebelião de um grupo de oficiais da Aeronáutica, em Aragarças, no Pará. A imagem do negociador vai se firmando"(Idem. Grifos nossos).

Na construção de uma memória para o futuro destacam-se aspectos que colocam em relevo a sua faceta de político negociador e, sobretudo, de herdeiro político de um dos maiores mitos da história brasileira: o presidente Getúlio Vargas. Afinal, o próprio Vargas dera-lhe a caneta que marca o fim da sua história de poder. Passa o legado e - na construção engendrada pelo texto apresentado como memória-sentese livre para "entrar na história". ${ }^{2}$

Do ponto de vista da significação, as cerimônias da televisão apresentam-se como históricas, isto é, destacam a idéia de ruptura ou de passagem a uma nova temporalidade. Os atos apresentados celebram valores centrais da sociedade, em um tom que exprime seu caráter sagrado.

No que diz respeito ao público, mobilizam vasto auditório, transformando-se em espetáculo remarcável. Introduz a idéia de experiência dividida e produz uma espécie de sentimento de solidariedade entre os telespectadores. Estes se reagrupam para se Comun. Inf., v. 7, n. 1, p.63-79, jan./jun. 2004 
transformar em participantes ativos daquela celebração.

Essas dimensões existem de maneira integrada e são essas características em conjunto que transformam a emissão em cerimônia.

\section{Morte de Tancredo: cerimônia coroamento}

O Brasil parou diante da televisão. Depois de 38 dias, assistindo, pela $\mathrm{TV}$, o desenrolar da doença e a agonia do primeiro presidente civil brasileiro após 20 anos de ditadura militar, o público presenciou ao vivo o desfecho. O locutor do Jornal Nacional anunciou em tom circunspeto e sombrio a morte de Tancredo Neves.

Nas vésperas de tomar posse no cargo máximo dirigente da nação, em março de 1985, Tancredo Neves foi acometido por uma grave doença. A partir daí, a cena política brasileira passou a existir nos boletins que o então porta-voz do Presidente, Antonio Brito, transmitia pela televisão.

Depois da lenta agonia, acompanhada via satélite, por meio das edições dos noticiários e de edições extras, que interrompiam a toda hora do dia as transmissões e irrompiam as casas, veio o desfecho: a morte, ocorrida em 21 de abril de 1985.

E a televisão cumpriu, mais uma vez, o ritual da cerimônia, transmitindo de maneira ininterrupta as imagens que expressavam a forma como o país encarava aquela morte. Na tipificação construída por Daniel Dayan (1996), a cerimônia da morte de Tancredo Neves, assim como de outras mortes midiáticas, como a do piloto de Fórmula 1 Ayrton Senna, do ponto de vista da transmissão da televisão é classificada como coroamento.

"Tancredo de Almeida Neves fez 75 anos no dia 4 de março. Mineiro de São João Del Rei, era o quinto filho de uma família de doze irmãos. Católico, foi coroinha. Primeiro a religião, depois a diversão, o futebol na praça".

A voz em off do apresentador materializa aspectos do personagem desde a mais tenra infância, quando ainda em São João Del Rei batia o sino da igreja entre uma jogada e outra de futebol. E continua: "Na adolescência, os momentos inesquecíveis de alegria". Ao fundo, imagens da cidade natal do personagem midiático.

Após apresentar resumidamente a história da vida do presidente até a sua chegada à Presidência da República, o apresentador segue Comun. Inf., v. 7, n. 1, p.63-79, jan./jun. 2004 
preparando o clímax da narrativa. "Vereador, Deputado, Senador, Ministro, Primeiro-Ministro, Governador e, agora, o político TN chegava à Presidência da República e estava pronto para receber o símbolo do mais alto poder político".

Mostrando a faixa presidencial, acrescenta:

"O presidente $\mathrm{TN}$ a conquistou com a emocionada confiança do povo brasileiro que o aclamou nas praças do Brasil inteiro. Em vida, o presidente não pôde vesti-la. Esta faixa, porém, lhe pertence e parte com ele para a eternidade. Só que agora, Tancredo morto, a faixa deixa de ser o símbolo da República, para se transformar numa Bandeira de amor que o Brasil coloca no peito dele para sempre".

Após o clímax, com um texto que apela sobretudo à emoção e destaca a participação popular, o apresentador traz a narrativa para $o$ presente:

"Voltamos ao Instituto do Coração, em São Paulo". Com essa frase, um novo personagem - o público - é introduzido na narrativa. $\mathrm{O}$ repórter, após rememorar os dias de internação do presidente, relembra a ação do público diante do anúncio da morte:

"O presidente permaneceu 38 dias internado, 25 dos quais no Instituto do Coração (...). Às dez horas e vinte três minutos desta noite terminou a agonia (...). Tão logo anunciada a morte do presidente, nós presenciamos cenas dramáticas aqui onde está o povo, em frente ao Instituto do Coração. Muitas pessoas passaram mal e foram socorridas por policiais".

Imagens de algumas pessoas carregando cartazes homenageando o Presidente e de outras chorando copiosamente construíam o cenário que convidava o público a participar da cerimônia da televisão.

"Neste momento, a situação é essa que vocês estão vendo: as pessoas estão emocionadas, praticamente não conversam; ficam apenas olhando para o prédio do Instituto do Coração e olhando para a movimentação dos jornalistas. Ali, mais atrás, permanece o boneco do Dr. Tancredo, um dos símbolos da campanha dele para a Presidência da República. E, próximo a ele, duas imagens: uma de Nossa Senhora Aparecida e outra de Jesus Cristo. Apesar dos pedidos, muita gente está chegando no Instituto do Coração. Em frente ao Centro de Convenç̃oses Rebouças, já temos uma Bandeira do Brasil estiada a meio palmo. É, portanto, um momento de grande emoção em São Paulo, neste canto da rua Ernesto de Faria, onde o povo está concentrado".

Comun. Inf., v. 7, n. 1, p.63-79, jan./jun. 2004 
O público é o principal ator da emissão. A tristeza, a dor, a emoção são construídas em torno dos personagens anônimos.

"Em frente ao Instituto do Coração em São Paulo, o povo começa a cantar a música 'Oh... Minas Gerais, quem te conhece não esquece jamais; Oh.. Minas Gerais'. Todo esse pessoal que está aqui a cada momento falam palavras; gritam frases em homenagem ao Presidente Tancredo Neves".

Apresentando todas as características de um ritual, as cerimônias da televisão são construídas numa espécie de festa-comunhão, na qual o telespectador é convidado a fazer parte. Dayan afirma que a cerimônia televisiva é uma espécie de religião da qual cada um participa à sua maneira, com seus atos particulares. Situando-se no limiar entre o sagrado e o profano, veicula, na verdade, atos de devoção, nos quais a crença é reforçada pela repetição e pela imitação.

Essas cerimônias são, antes de tudo, acontecimentos monumentais que se tornam públicos por meio das emissões e que pressupõem uma certa ritualização, onde a forma, a narrativa e a difusão são fundamentais.

A rigor, esses espetáculos transformam a experiência do telespectador em relação à mídia. A transmissão simultânea, ao mesmo tempo em que unifica áreas geográficas dispersas, cria uma temporalidade comum, ao interromper a seqüência da própria televisão, produzindo uma espécie de suspensão do tempo.

A televisão, como mostrou Raymond Williams (1990), é percebida pelo público num continuum incessante-uma espécie de supertexto - no qual os limites entre os programas tendem a se apagar, ainda que os produtores e o público percebam a existência, dentro desse texto, de narrativas diferenciadas.

Para Williams, a televisão é resultado da combinação e desenvolvimento de formas anteriores de comunicação e de formas engendradas pelo próprio meio, ainda que não possam ser caracterizadas como inovações absolutas.

Formas culturais anteriores à televisão - como a notícia, o debate, o drama, o filme, o esporte, a propaganda, etc - permaneceram, ainda que transformadas, ao ser apropriadas. Há, entretanto, outras formas que foram construídas pela própria televisão. É o caso do dramadocumentário, que mescla características do drama com a própria reportagem jornalística.

Assim, a experiência do público diante da televisão é de recebimento Comun. Inf., v. 7, n. 1, p.63-79, jan./jun. 2004 
de um fluxo incessante de imagens, que se sucedem num ritmo acelerado e cuja aparência parece não ter encadeamento lógico. Mas o que é oferecido é um fluxo planejado, no qual cada seqüência é transformada pela inclusão de um outro tipo de seqüência que, justapostas, compõem o fluxo real.

A própria figura do zapeador contemporâneo, o telespectador que assiste à televisão saltando de um canal a outro de maneira incessante, mostra como se materializa, na emissão televisual, a experiência do fluxo.

Mas a par desse tipo de narrativa existe outra tipologia de programas que merece, por parte do público, um tipo de atenção diferenciado: são as cerimônias televisuais, um gênero restrito à televisão e que se distingue das outras emissões.

Caracterizando essas cerimônias em três grupos - conquista, confronto e coroamento -, Daniel Dayan e Elihu Katz servem-se da teoria weberiana, na qual cenários recorrentes levam a estratégias de legitimação. Ainda que um cenário dominante possa ser especificado, ele nuncaé unívoco. Assim, uma cerimônia, que poderia ser classificada como conquista pode se transformar em confronto e terminar em coroamento.

A conquista, segundo eles, são aqueles acontecimentos que valorizam a transgressão das regras, pressupondo ato voluntarista, deliberado, que ultrapassa os limites do possível. A característica mais marcante é a sedução carismática. A chegada do homem à Lua, em 21 de julho de 1969, primeira emissão cerimonial da televisão brasileira, pode ser caracterizada dessa forma.

Já no confronto não há transgressão das regras. São acontecimentos governados por regras explícitas, determinadas pelos representantes do grupo. Temporal e espacialmente limitadas, essas cerimônias mantêm uma relação intrínseca com a vida quotidiana. Uma outra característica é o seu caráter cíclico, que afirma a multiplicidade de pontos de vista. Há no confronto, o reconhecimento oficial da legitimidade do conflito. A transmissão da Copa do Mundo é um exemplo de cerimônia televisual desse tipo.

No coroamento observa-se o caráter cerimonial elevado à máxima proporção. Situando-se entre a natureza e a história, como um rito de passagem, caracteriza-se pela tensão narrativa que cria, ao mesmo

Comun. Inf., v. 7, n. 1, p.63-79, jan./jun. 2004 
tempo em que apela a laços do passado, levando o público a refletir sobre o próprio fluxo da história. A transmissão da morte de Tancredo Neves e de Ayrton Senna são exemplos de cerimônias coroamento.

No dia morte de Tancredo, a televisão se ocupou em reconstruir a sua trajetória, mostrando o fluxo da história de maneira particularizada. Nesse fluxo, interessava reportar aspectos que mitificavam a vida do ex-presidente, ao mesmo tempo em que o aproximavam do público.

A emissão é dividida em duas partes: dor e luto no hospital, e o Brasil que reza e sofre por Tancredo. Na primeira parte, as informações sobre o luto oficial e o cortejo, com detalhamento do seu trajeto percorre aAv. Rebouças, a Av. Brasil, passando em frente ao Obelisco do Movimento Constitucionalista de 1932, Parque do Ibirapuera; Av. 23 de Março; Av. Rubem Berta, chegando depois ao Aeroporto de Congonhas - são entremeadas por outras informações, como a missa a ser realizada no Instituto do Coração, em São Paulo.

Na segunda parte, o que importa são as ações do público, as imagens da mobilização nacional. Fiéis rezando nas igrejas, pessoas de todas as idades rezando nas ruas, a emoção e a comoção nacional como símbolo histórico daquele desfecho. Em off, a voz do locutor complementa:

"Tempo de Quaresma. No Brasil inteiro, orações; fé em Deus. No tempo da Quaresma, orações e muita força; palavras de fé e de coragem. Tempo de oração; todo mundo sofrendo. O povo brasileiro foi amigo e carinhoso desde o começo. O movimento no hospital de base em Brasília mostrava o desejo que todos tinham de animar, de confortar o presidente. O país fica preocupado e acompanha pelos jornais e revistas. Orações no Brasil de todos os credos, de todas as cores, de todas as idades".

A mescla do sagrado e do profano sobressai na emissão. Mulheres cantando numa igreja católica, pessoas na umbanda pedindo pelo presidente, o pregador protestante dizendo "aquele que Deus levanta, ninguém pode derrubar". Japoneses fazendo oração, pessoas na Arquidiocese de São Paulo, fiéis na Matriz do Pilar, em São João Del Rei. Outros ajoelhados, orando, na Catedral de Brasília; cantando música pelo Brasil e por Tancredo, que passa a ser construído como símbolo da democracia brasileira. Imagens com suas fotos formando um cartaz, que é exposto nas janelas das casas.

Explorando o entorno do acontecimento, a emissão é construída Comun. Inf., v. 7, n. 1, p.63-79, jan./jun. 2004 
do centro para a periferia da notícia. Assim, na emissão que anunciou a morte de Tancredo Neves importava recordar fatos de sua vida passada que, narrados numa cadência particular, construíam um personagem a ser imortalizado para a história. Na transmissão importava lembrar o fato de o presidente ser herdeiro da caneta de Getúlio Vargas, líder político carismático maior do país. Importava também relembrar sua trajetória em favor do restabelecimento da democracia no país, a sua participação no movimento Diretas Já! A imagem da cantora Fafá de Belém entoando o Hino Nacional com nova roupagem musical dava à cena midiática a solenidade necessária naquele momento, ao mesmo tempo em que instaurava uma nova comunhão nacional em torno dos símbolos da pátria. A bandeira do país tremulando em repetidas cenas, ao lado de bandeiras brancas, símbolos do adeus, tendo como fundo musical o hino entoado pela multidão, transformava também Tancredo Neves num dos símbolos de uma nacionalidade coroada pela cena da TV.

Cada um desses símbolos recebia nova roupagem, materializando a introdução de uma nova temporalidade. O Hino Nacional recebeu nova harmonização, na qual a melodia foi modificada, ainda que a letra permanecesse inalterada. E a música que falava do estado natal do presidente transforma-se numa espécie de hino particular de Tancredo Neves. Com isso, monumentalizava-se os símbolos da pátria, ao mesmo tempo em que se dava a eles outra significação. Era como se o país, naquele instante-comunhão, governado pelo aparato televisivo, criasse novas simbolizações para velhos ícones de sua nacionalidade.

A mídia, no caso a televisão, distribui nessas cerimônias papéis aos atores e aos espectadores, especificando sua natureza. Assim, pode sublinhar os antagonismos (confronto), indicar a superação de um obstáculo (conflito) ou convidar os espectadores a repetir a cerimônia, precisando o sentido dos símbolos utilizados (coroamento). É a mídia também que marca os contornos do acontecimento, promovendo a sua separação dos elementos da vida quotidiana. É mediante a narrativa que ocorre, portanto, a definição oficial do acontecimento.

Também a televisão estabelece a melhor forma narrativa para o acontecimento. Assim como a história não pode ser concebida fora das narrativas nas quais ela se anuncia (White, 1994), também o jornalismo não escapa de suas próprias escolhas narrativas. Os Comun. Inf., v. 7, n. 1, p.63-79, jan./jun. 2004 


\section{6}

acontecimentos, a rigor, são construídos seguindo diferentes fórmulas narrativas. Um mesmo acontecimento, por exemplo, a transmissão da Copa do Mundo, pode assumir a idéia de uma batalha entre continentes ou entre rivais (Brasil e Uruguai), parada festiva, arena de disputas de natureza política. É, pois, um problema de natureza estratégica, em que o que está em jogo é o poder de nomeação exercido pela mídia. A forma narrativa determina, portanto, a própria significação política do acontecimento.

Mas as cerimônias midiáticas representam o acontecimento e oferecem ao público a possibilidade de participar daquela "experiência festiva". Para isso, o texto se vale da retórica da denegação e da recriação do acontecimento. Nega-se toda alteração no acontecimento original, criando um discurso de compensação, em que a narrativa é instrumento de representação do acontecimento cerimonial, isto é, vetor de seu contágio. Ao lado disso, a encenação estabelece as fronteiras, dissociando o que deverá permanecer como resíduos, vestígios, restos e farrapos, e o que deverá ser esquecido. Essas etapas, ainda que invisíveis na construção da narrativa, são corolários fundamentais da recriação do acontecimento. E é essa recriação que lhe dá sentido.

Nas emissões da agonia do presidente Tancredo Neves e, sobretudo, na transmissão que marca o desfecho do acontecimentoa morte-há toda uma escolha de elementos narrativos que destacam a comunhão e a comoção popular em relação à perda, construída como irreparável. O acontecimento, constituído durante mais um mês, apelava nas suas fímbrias narrativas para a emoção e a crença de que a fé do povo em torno da idéia de recuperação do presidente poderia operar milagres. As cenas da população orando na porta do hospital onde estava internado o presidente eram exibidas recorrentemente. As orações, as preces, as mensagens, as promessas, enfim, todos os elementos da fé popular foram explorados ao máximo nas emissões que antecederam e prepararam a cerimônia televisiva final. Assim, na emissão da morte, o que se destacava era, uma vez mais, a comoção popular e as imagens da fé popular.

Existe, portanto, também nessas cerimônias, a permanência da idéia de fluxo televisual. $\mathrm{O}$ acontecimento que marca o desfecho da trama congrega elementos de narrativas anteriores que preparam o seu desenrolar. E a televisão fornece elementos que o público espera reconhecer. Comun. Inf., v. 7, n. 1, p.63-79, jan./jun. 2004 
Paralelamente, a emissão desloca as fronteiras do acontecimento, configurando-o entre a cerimônia e a ficção. Comparadas à dramaturgia das notícias, as informações da emissão cerimonial deslocam o sentido da natureza temporal do acontecimento. Anarrativa é relatada de forma seqüencial e contínua, enquanto nos telejornais os acontecimentos apresentam espécies de vazios de sua dimensão temporal. No que diz respeito ao espaço, evidenciam-se as chamadas continuidades espaciais. Assim, os comentaristas aparecem como elementos centrais da narrativa, explorando diversos pontos de vista. Isso permite ao público assistir ao acontecimento também pelos olhos de seus participantes ativos.

As cerimônias também evocam símbolos. Os atores dessas cerimônias ficam encobertos pelas realidades míticas que elas encarnam. A televisão acompanha a narrativa dos gestos oficiais como uma espécie de crônica afetiva dos acontecimentos. Na transmissão da morte de Tancredo, por exemplo, mais do què os planos de seu sucessor, mais do que a fala do vice-presidente que ocupava o seu lugar, interessavam a dor do povo e a imagem de comoção da população que rezara por mais de um mês pela recuperação do presidente.

Oferecendo ao telespectador um novo tipo de experiência, acessível no espaço privado da casa, possibilita a sua participação em todas as fases do ritual, eliminando tudo o que possa vir a ser obstáculo. Para isso é preciso descontextualizar o acontecimento, acabando com a fronteira entre entretenimento e notícia, em favor de uma terceira possibilidade: uma espécie de tempo híbrido, no qual irrealidade $\mathrm{e}$ realidade criariam uma terceira dimensão.

Organizando o cenário da entrada do público nesse universo, a televisão também desagrega gradativamente o próprio acontecimento, ajudando o telespectador a se readaptar no mundo. Mas antes é necessário iniciar o telespectador para que o evento esteja a seu alcance, aberto à sua participação. A excepcionalidade pode ser percebida na voz dos comentaristas e nas palavras que empregam. A concisão dá lugar a uma linguagem ornamental e por vezes lírica. Aprosa informativa transforma-se em poesia celebratória.

Antes da emissão, há a difusão de imagens de arquivo, complementadas com informações sobre a trajetória do personagem, transformando o telespectador em alguém que pode - porque possui Comun. Inf., v. 7, n. 1, p.63-79, jan./jun. 2004 
o conhecimento indispensável para isso - acompanhar a narrativa. Há toda uma retórica pedagógica de fornecer conhecimento, ultrapassando a defasagem cultural do próprio telespectador, que, assim, se sente apto a acompanhar mentalmente os gestos daquele ritual.

$\mathrm{O}$ acontecimento é enfim monumentalizado pela retórica narrativa: efeitos especiais, montagens e justaposições transformam a cena transmitida pela televisão em ícone da memória coletiva. Agrandiosidade das cenas - grandes espaços abertos, com a multidão tornando-se ator amorfo e identificado da trama-dá o aspecto monumental necessário e mostra a amplificação dessas mensagens, que parecem abarcar todos os telespectadores na mesma festa-comunhão. A música ao fundo, o espetáculo dos símbolos nacionais tremulando sobre a forma de bandeiras de todos os tamanhos dá nova cadência ao acontecimento. E esse ritmo permite converter uma assembléia em comunidade.

O discurso reflexivo e nostálgico desenvolve-se a partir da idéia de que participar daquela cerimônia torna os telespectadores um mesmo conjunto. O papel da televisão não é apenas representar o acontecimento, mas ilustrar a forma como este se difunde, contagiando a massa dos telespectadores. A emissão propõe, enfim, que todos os espectadores assistam, simulando uma igualdade entre todos.

\section{Abstract}

The objective of this text is to analyze how the Brazilian television constructs the representation of the death. We intend to show that, from the transmission of Jornal Nacional on, by Rede Globo de Televisão, showing the end of the agony of the president-elect, on 21 April 1985, TV constructed a ceremony about the death event. Using many strategies, the online coverage of the funeral of Tancredo Neves as Media's events produces a kind of time pause and tries to make the public adhere to the spectacle. The text presents some results of the research "Media and Ceremonies, an analysis of the ceremonial model of the Brazilian TV", funded by CNPq.

Keywords: Television - Events - Death - Tancredo Neves

\section{Referências}

DAYAN, D e KATZ, E. La télévision cérémonielle. Paris: PUF, 1996 DAYAN, D. et KaTZ, E. Media Events. The Live Broadcasting of Comun. Inf., v. 7, n. 1, p.63-79, jan./jun. 2004 
History. Cambridge: Havard University Press, 1992.

WILLIAMS, Raymond. Television - technology and cultural form. Londres: Routledge, 1990.

WHITE, Hayden. "O texto histórico como artefato literário". In: Trópicos do Discurso. Ensaios sobre a crítica da cultura. São Paulo: Edusp, 1994.

Edição do Jornal Nacional - TV Globo, de 21 de abril de 1985.

\section{Notas}

${ }^{2}$ A expressão remete à frase final da carta testamento de Getúlio Vargas: "Saio da vida, para entrar na história".

Comun. Inf., v. 7, n. 1, p.634-79, jan./jun. 2004 